\title{
10 \\ Tratamento do Capital \\ nas Sociedades Cooperativas Brasileiras
}

\author{
Vergílio Frederico Perius \\ Professor UNISINOS
}

\section{Histórico}

A história inicial do sistema cooperativo nunca tributou muita importância à formação de capital nas cooperativas. A primeira cooperativa alemã de consumo: "Associação do Pão» (1847) não tinha capital próprio em seus registros contábeis, o que vale dizer que o capital próprio não era essencial ao conceito de cooperativa. De igual modo, o Direito Cooperativo Brasileiro (Decreto n. 22.239 de 1932, art. 30, inc. 3. $^{\circ}$ ) consagrou a existência de cooperativas, como as Caixas Rurais Raiffeisen, sem a exigência de capital social.

Mesmo que o capital não fosse essencial, qual a função que realmente exerce? O capital é «meio-função» e sua funcionalidade se presta para realizar a co-participação das atividades empresariais entre os sócios e as cooperativas. Credencia ao uso do voto unipessoal, possibilitando a gestão democrática e assegura a estrutura personalística das sociedades cooperativas. O essencial, portanto, não é o capital, mas os sócios. Como sociedades de pessoas, a união das mesmas constitui a base orgânica da Sociedade Cooperativa, em contraposição e indiferença até às sociedades de capital, nas quais os sócios têm, em regra, um único objetivo, o de obter lucros «na proporção do capital investido» ${ }^{1}$. Nestas, o capital é fim, para gerar lucro na proporção dos investimentos. Nas sociedades de capitais o «affectio societatis» está

1 Franke, Walmor. Direito das Sociedades Cooperativas - Direito Cooperativo. São Paulo: Saraiva, 1973, p. 12. 
em função do ânimo de lucro ao passo que nas sociedades cooperativas, predomina a intenção de cooperação e colaboração dos seus sócios. Assim, o capital nas cooperativas é «meio-instrumento para utilização de seus fins, não merecendo uma posição à parte e mesmo privilegiada como nas sociedades tipicamente de capitais» ${ }^{2}$.

O capital sendo meio, reflete a natureza econômica e social das sociedades cooperativas, e essa característica fica clara a partir da análise da relação estabelecida entre as quotas-partes e a função prestadora de serviços das cooperativas, uma vez que «as quotas de cooperativas poderiam ser descritas mais exatamente como contribuições de direitos a serviços ou direito à participação» ${ }^{3}$. As sobras originadas das operações, por sua vez, têm como critério distributivo não o capital, mas o volume de participação operacional de cada sócio, prevalecendo assim, a contribuição pessoal sobre a patrimonial.

Consegue-se diferenciar mais claramente a fundamental distinção existente entre uma sociedade cooperativa e uma sociedade de capital, a partir do vínculo pessoal e financeiro que se estabelece entre os sócios e as respectivas sociedades. A participação financeira decorre na sociedade cooperativa do vínculo estabelecido a partir do candidato ter sido aceito no quadro associativo. Na sociedade de capital ocorre o inverso: é o vínculo financeiro que gera uma interdependência pessoal. Dessa forma o sócio de uma cooperativa se relaciona com a mesma não como decorrência de participação no capital, mas como conseqüência de um relacionamento personalístico. Veja-se:

a) a sociedade cooperativa, em sua fase de constituição, prescinde de um capital mínimo integralizado para sua constituição. Entre os requisitos mínimos exigidos para o ato constitutivo (art. 15 da Lei n. ${ }^{\circ}$ 5.764/714) deve estar declarado apenas o valor e o número das quotas-partes de cada associado fundador. Os sócios fundadores integralizam o capital depois da cooperativa ter adquirido sua personalidade jurídica;

2 Bulgarelu, Waldírio. Regime tributário das cooperativas. São Paulo: Saraiva, 1974, p. 127.

3 Utuml, Américo e outros. A problemática cooperativista no desenvolvimento econômico. São Paulo, 1973, p. 294.

4 A atual lei em vigor (Lei n. ${ }^{\circ} 5.764$, de 16 de dezembro de 1971) sofreu revogação pela Constituição Federal de 1988, em várias disposições. 
b) a integralização do capital é ato posterior e complementar ao da inscrição no quadro de associados e isso se depreende das próprias fases da matrícula, a saber:

$-1 .^{a}$ aprovação do pedido de ingresso;

-2. ${ }^{a}$ subscrição de quotas-partes e;

-3. ${ }^{\text {, }}$ a assinatura do Livro de Matrícula. O candidato a sócio em cooperativa adquire essa qualidade associativa antes mesmo da integralização das quotas-partes. A subscrição faz parte do corpo de normas às quais se submeteu livremente.

Basta, portanto, a submissão às normas internas da sociedade cooperativa para adquirir a qualidade de associado; a subscrição e a conseqüente integralização do capital são atos complementares, conforme estatui o art. 30, Lei n. ${ }^{\circ}$ 5.764/71. Ambos são conseqüência do ato de aceitação ou de ingresso, que se consolidam pela aprovação da proposta de admissão por parte da administração;

c) a natureza jurídica das quotas-partes, por serem intransferíveis, inseparáveis dos associados, não serem herdadas, confirma tratar-se de «um vínculo jurídico de ordem pessoal, não patrimonial» ${ }^{5}$, que se estabelece entre a cooperativa e os associados. Mesmo havendo transferência das quotas-partes, com o necessário consentimento (art. 26, Lei n. ${ }^{\circ} 5.764 / 71$ ) não ocorre transferência da qualidade de associado para outro associado. Com a morte do associado também não ocorre transferência de capital aos herdeiros do "de cujus», visto que a morte de pessoa física exclui a qualidade associativa da mesma pessoa (art. 35, inciso II). Desse modo a qualidade nominativa das quotas-partes tira o caráter especulativo do capital;

d) os motivos que determinam o término da qualidade de sócio repousam na pessoa dos associados e estes motivos afastam a possibilidade da permanência de sócio em razão de meros vínculos contratuais. A vinculação estatutária é institucional e não contratual. A demissão (art. 32), a eliminação (art. 33), e a exclusão (art. 34) encerram a relação institucional ou o vínculo pessoal. O vínculo patrimonial por sua vez não se extingue com o ato de término do vínculo associativo, o que confirma mais

5 FILHo, Flávio Luz. O direito cooperativo. Rio de Janeiro: Irmãos Pongetti Editores, 1962, p. 102. 
ainda a relação personalíssima existente entre cooperativas e associados;

e) a existência de livro de matrícula e a obrigatória inscrição nele dos sócios manifestam o caráter da pessoalidade (art. 23 e art. 30). Isso credencia à sociedade cooperativa uma posição de confiança no interesse da segurança jurídica. Pelo art. 23, inciso I e II deduzse a força da pessoalidade. A participação no capital fica averbada em conta corrente dos associados (art. 23, inc. III).

Conclui-se daí, que as relações sócio-cooperativa têm natureza institucional, baseado na estrutura personalística da sociedade cooperativa e não na participação financeira. O sistema cooperativo não suprime o capital, mas tira-lhe o caráter de regulador da produção. Como o capital não exerce a primazia nos fatores da produção, fica afastado o eventual domínio econômico da maioria de capitais e preservada a estrutura democrática da sociedade cooperativa.

\section{Estímulos para capitalização}

A falta de consciência dos associados sobre o ato de submissão ao ingressar numa sociedade cooperativa, traz efeitos que, mas tarde, fatalmente se manifestarão como:

— na apatia e indiferença dos sócios pela administração e pelo controle da empresa cooperativa. A reduzida participação nas Assembléias Gerais constitui o exemplo mais aparente desse fenômeno;

- na posição que determinados sócios assumem, denominadas de: «Saboteurs» e de «Outsider». O sócio «outsider» se beneficia de um bem não individual, sem pagar seu custo. $\mathrm{O}$ «Saboteurs» promete sua participação no custo da produção de um bem não individual, mas na verdade não participa. Os dois tipos de sócios apresentam formas de parasitismo, visto que é «parasita quem vive às expensas de outros ${ }^{6}$. Em relação à espécie humana, o parasitismo se define como sendo, "aquele que consiste em viver do produto do trabalho de outro» ${ }^{7}$.

6 GIDE, Charles. El cooperativismo. Intercooperativismo. Buenos Aires, 1974, p. 188.

7 GIDE, Charles. Op. cit., p. 191. 
Se a doutrina e o direito cooperativo tratam o capítulo do capital como tema de relativa importância, o mesmo não ocorre na área dos pensadores econômicos da ciência cooperativa, que vêem a capitalização cooperativa como tema de fundamental importância e fator de crescimento e de eficiência das empresas cooperativas. O pensador da economia cooperativa pergunta como incentivar os sócios com o reconhecimento da necessidade de gerar capital? A ausência de estímulos financeiros se constitui no maior entrave para possibilitar o crescimento das cooperativas, sustentado na base da capitalização própria do quadro social, pois "os juros pagos não atraem os capitalistas» ${ }^{8}$. 0 mesmo raciocínio foi externado por Waldírio Bulgarelli: "pois o simples juro módico a que alude a doutrina cooperativista e a própria legislação, não seria bastante atrativo para levar os produtores rurais em massa a uma subscrição acentuada» ${ }^{9}$.

A limitação da taxa de juros sobre o capital e a limitação de um voto por pessoa geram para a empresa cooperativa a obrigação de oferecer estímulos não-financeiros que induzam os sócios a capitalizarem e a continuarem a operar. Trata-se de encontrar estímulos sem o conseqüente direito de adquirir mais poder decisório da administração cooperativa. Sabe-se que os sócios potencialmente mais fortes para aquisição de novas quotas-partes, questionam mais poder de decisão, uma vez que suas responsabilidades sociais correspondem ao capital subscrito. Sabe-se também que o sistema cooperativo não permite compensações como prêmio de capitalização e conseqüentemente a fraca capitalização é um «... inconveniente, pois, toda organização cooperativa que não encara com honestidade a necessidade e, a apropriação de resultados positivos do balanço e como isto, infelizmente, deturpa a ação cooperativista» ${ }^{10}$.

A questão fundamental se concentra no seguinte dilema: como superar o desestímulo em capitalizar, em razão da limitação do voto unipessoal?

8 PINHO, Diva Benevides. A Doutrina Cooperativa nos Regimes Capitalista e Socialista, p. 94.

9 Bulgarelli, Waldírio. Op. cit., p. 130.

10 Utuml, Américo. Op. cit., p. 36. 
O caminho para superação da questão poderá dar-se pela:

2.1) não-devolução em «espécie» das sobras, que vincula o oferecimento de melhores preços, menores custos ou a melhor prestação de serviços;

2.2) forma compulsória de capitalização na base da produção entregue na cooperativa;

2.3) formação de capital rotativo;

2.4) correção monetária do capital;

2.5) taxação das contas-correntes.

O exame das sugestões abaixo, sem exclusão de outras, merece atenção:

\subsection{A não-devolução, em «espécie», das sobras}

A proposta vincula o oferecimento de melhores preços, menores custos ou a melhor prestação de serviços:

A Doutrina Cooperativa considerou o princípio da devolução das sobras como o "golpe de gênio» dos Rochdalianos, na expressão de Charles Gide. Todas as legislações sobre Sociedades Cooperativas consagram o retorno pelos critérios de operacionalidade. Segundo Gide, seria esse o princípio que teria aproximado o sistema cooperativo ao modelo capitalista, por remunerar o esforço e a capacidade individual. Reinhardt opina diferente: "Trata-se, segundo o Direito Societário, de uma obrigação enraizada na Cooperativa para com os seus sócios» ${ }^{11}$.

A forma de devolução das sobras, porém, poderá ser direta ou indireta. A primeira prevê a devolução «em espécie». A segunda, na forma de um crédito para nova prestação de serviços ou na retenção e simultânea transformação das sobras em novas quotas-partes. A forma indireta se relaciona com os investimentos e sua destinação é dada pelos próprios associados. Acontece que normalmente o interesse dos sócios nas Assembléias Gerais se manifesta pela distribuição direta das sobras, o que conflita com os interesses de uma administração preocupada com os aspectos de capitalização nas cooperativas. Uma dinâmica administração tem os interesses orientados no crescimento da cooperativa e para isso precisa de capitalização. O superávit

11 ReInHARDt. Zeitschrift für das gesamte Genossenschaftswesen, p. 311. 
ficaria retido e significará o investimento dos sócios, pois, «se uma Cooperativa procura crescer, será esse um dos caminhos, retendo os recursos a serem distribuídos» ${ }^{12}$.

Para alcançar esse efeito será preciso que a administração demonstre aos sócios as vantagens desse investimento. Aqui começa o complexo caminho de crescimento das empresas cooperativas, sustentado por investimentos colocados à disposição pelos próprios associados, pois nem todos os sócios aceitam a tese do crescimento empresarial na modalidade em exame. Por outro lado, a baixa remuneração do capital investido não consegue atrair o investidor cooperativo. Nasce daí o conflito entre sócios e a administração. Os interesses não são mais idênticos. A existência desse conflito coloca em dúvida a tradicional teoria da fidelidade entre sócios e administradores. Quanto maior for o número de sócios na cooperativa, maior será o conflito de interesses. A confirmação da existência desse conflito nos é dada por um dos expoentes da ciência cooperativa, o Dr. Eschenburg: «Com o crescimento da empresa orgânica, a administração se emancipou e a original identidade da promoção dos sócios e da política empresarial se transformou num problema $)^{13}$. Constatada a existência do conflito da não-identidade de interesses entre sócios e administração, significa que a administração poderá gerir os negócios da cooperativa contra os interesses dos próprios sócios. Questiona-se se o fato revela uma traição à própria instituição cooperativa, que se caracteriza como sociedade de pessoas, com estrutura democrática, onde os sócios tomam as decisões e a administração é a fiel executora da política fixada pelos associados?

Por ora pergunta-se sobre os caminhos da superação do conflito resultantes da não-identificação de interesses quanto à distribuição de sobras. Eschenburg parte do princípio da supremacia da administração sobre os sócios. Na análise do comportamento dos sócios nas Assembléias Gerais e da própria ordem do dia, conclui-se, pelos estudos do mesmo autor, de que a administração, centralizando melhores informações, «orienta» facilmente as Assembléias Gerais nos interesses de sua política de gestão. Segundo o mesmo autor, uma eventual «agitação» teria custos muito elevados, para que seja negada aprovação às

12 Reinhardt. Op. cit., p. 315.

13 EschenburG, Rolf. Genossenschaft und Demokratie, Em Zfgg - Caderno 2, 1972, p. 32 . 
propostas da administração. Essa posição de supremacia levou as cooperativas alemãs, por exemplo, a uma excelente capitalização: «50 \% e, em algumas Cooperativas de Consumo, a não-devolução das sobras forma até $90 \%$ do capital próprio» ${ }^{14}$.

Pode-se admitir assim a não-devolução das sobras «em espécie» como forma de compensar a não-atratividade dos sócios na capitalização voluntária. A frágil estrutura na formação do capital poderá ser superada na medida em que a administração exercer uma supremacia sobre os sócios, ou na medida em que forem consagrados nos Estatutos Sociais as retenções de sobras à título de capitalização. Vincula-se, porém, tal política administrativa com o oferecimento de melhores preços, menores custos ou uma melhor prestação de serviços por parte das cooperativas.

Qual o custo da prestação de serviços e qual a política de preços que a empresa cooperativa deve perseguir nas suas operações? Que vantagens econômico-financeiras deve ela oferecer aos sócios, como estímulo de novas operações, capazes de neutralizar a posição do sócio "outsider», do sócio "saboteur»? Como obter sobras, que canalizados à título de quotas-partes, poderiam superar os graves problemas de capitalização nas cooperativas?

A fixação dos custos decorre da prestação de serviços oferecidos pela empresa cooperativa. Essa, como empresa comum ou «empreendimento negocial comum», elimina o mercado entre o empreendimento cooperativo e as economias dos sócios. Os negócios jurídicos realizados entre ambos denominam-se de atos cooperativos. Não há de se falar de contratos, mas de um identidade jurídica. A identidade jurídica se manifesta pela estrutura personalística e democrática, que identifica o portador das quotas-partes com o beneficiário dos serviços prestados pela cooperativa. A identidade leva à mutualidade, executada na prática pela prestação de serviços sem lucro (critério da mutualidade) e sem intermediário (critério de identidade). A identidade fundamenta a mutualidade para a obtenção de fins comuns. Não há existência de mercado, nem contratos de compra e venda nas operações denominadas de atos cooperativos. Conclui-se daí o caráter não-lucrativista nas operações entre sócios e a empresa cooperativa. Face o caráter delineado não há razão para maximizar os custos. A

14 Grossfeld, Bernard. Genossenschaft und Eigentum, Tübingen, 1975, p. 12. 
cooperativa, portanto, não deve operar com custos maiores do que os necessários à cobertura dos próprios custos. Isso significaria: a empresa cooperativa deve oferecer aos associados bens e prestação de serviços ao custo mais baixo possível, ou seja, ao custo da própria prestação ou do bem servido.

O sócio cooperativo está interessado em obter com suas operações a melhor vantagem econômico-financeira possível. Sua disposição em cooperar está em relação direta com as vantagens que a cooperativa Ihe oferece, comparativamente ao mercado. A cooperação é dever, enquanto a mesma oferecer benefício maior que o da concorrência. Exclui-se toda e qualquer cooperação idealista, sustentada na idéia de participação cooperativa por «altruismo». O «homo cooperativus» é uma ficção. Trata-se sempre de um «homo economicus»que entra em negociações, pois «cada um dos cooperativados estará orientado no seu individual interesse em obter o máximo de lucro individual da cooperação» ${ }^{15}$.

Qual a política comercial que a administração deve perseguir para oportunizar benefícios máximos aos sócios? A questão deve ser analisada conforme cada tipo de cooperativa. Assim, o sócio de uma cooperativa agropecuária espera o preço mais alto sobre a produção entregue. Os associados de uma cooperativa habitacional desejam pagar a menor prestação de amortização ou a menor taxa de uso. Trata-se de conciliar esses interesses dos sócios com a administração de tal forma que a cooperativa ainda assim consiga obter sobras para serem canalizadas para a capitalização. A administração cooperativa deve, portanto, orientar-se na melhor prestação de serviços, capaz de remunerar (no caso de uma cooperativa agropecuária) ou gerar uma economia (no caso de uma cooperativa de consumo) ao associado à níveis superiores aos serviços prestados pelo mercado e ainda oferecer sobras para gerar capital. Vê-se que é inseparável a tese da capitalização na base da não-devolução das sobras «em espécie» com a política da melhor prestação de serviços, que se resume nos menores custos e nos melhores preços.

Neste contexto é equivocada a política de maximizar fundos indivisíveis com as sobras.

15 EsCHENBURG, Rolf. Ökonomische Theorie der genossenschaftlichen Zusammenarbeit. Tübingen, 1971, p. 92. 
Está cedendo lugar a práxis cooperativista de contabilizar sobras a favor de fundos indivisíveis, que não pertencem a ninguém, mas constituem propriedade coletiva e, em caso de liquidação (havendo remanescente) eram destinados ao Banco Nacional de Crédito Cooperativo S/A B.N.C.C e hoje ao Banco Central do Brasil - BACEN.

Diversas cooperativas, procederam alterações estatutárias, extinguindo os fundos indivisíveis e transformando-os em formas de capitalização, nominando os resultados gerados no exercício social em conta individual e não mais coletiva.

Esse comportamento constitui-se em importante conquista para o sistema cooperativista, porquanto significa um instrumento de correção dessa "socialização» dos resultados do trabalho e aproxima mais o associado à condição de dono do capital e usuário dos serviços que lhe são prestados pela sua cooperativa. Sentindo-se mais dono, o sócio das cooperativas, por certo, exercerá, com mais energia, seus direitos na tomada de decisões e na própria vida operacional das cooperativas.

O mecanismo adotado não coloca em risco a capitalização das cooperativas, uma vez que os créditos positivos são lançados no não-exigível. Aliado ao fato de que os Estatutos Sociais estabelecem salvaguardas de proteção do capital em eventual hipótese de retirada massiva de associados, se consegue, efetivamente, individualizar os resultados produzidos, sem prejuízo do fortalecimento da empresa cooperativa como coletividade.

\subsection{Forma compulsória de capitalização na base da produção entregue na cooperativa}

O processo da capitalização compulsória na base da retenção de determinado percentual sobre a produção entregue está consagradado em quase todas as cooperativas agropecuárias. Muitas cooperativas conseguiram elevar o capital social, notadamente aquelas que operam com o trigo, soja, café, cacau, algodão, arroz e cana-de-açúcar. Em decorrência, os produtores deste cereal elevaram seu capital nas empresas cooperativas de tal forma que uma minoria de associados - grandes produtores - contabilizam a maioria do capital. A adoção desse processo de capitalização em relação à outros produtos entregues na cooperativa tem gerado um grave risco, que é o do desvio da produção, motivado exatamente pela obrigatória entrega dos produtos, com um desconto, à título de capitalização. 
Face a não-atratividade em capitalizar, em razão do reduzido rendimento do capital investido na cooperativa, face ao sistema de recebimento de produção da maior parte das cooperativas sustentado nos preços do dia, em abandono dos preços médios - o que transformou as operações entre sócios e cooperativas praticamente em atos comerciais e não atos cooperativos, face ao reduzido poder de concorrência que muitas cooperativas sofrem em relação à empresas privadas nãocooperativas e empresas estatais na manutenção de uma política de bons preços aos produtos a serem entregues nas cooperativas, esse critério de capitalização não tem conseguido superar as tradicionais dificuldades relacionadas com o capital social. Tem ademais gerado uma estrutura administrativa anômala em muitas cooperativas, uma vez que, a estrutura dessas cooperativas relaciona-se diretamente com a estabilidade do quadro associativo, onde os detentores de grandes capitais têm — via de regra- maior interesse e participação na vida societária e empresarial da cooperativa. Assim, muitas administrações cooperativas estão centralizadas nas mãos de produtores rurais mais capitalizados em decorrência de maior interesse pela administração. Os associados de menor capitalização, naturalmente com menores volumes de entrega de produção, estão mais distanciados da administração.

Evidente que colabora para a formação dessa estrutura de capitalização a questão fundiária. Sem alteração dessa estrutura, a desproporção em termos de posse e sustentação do capital social nas cooperativas irá se agravar, na hipótese de permanecer esse critério de somar capitais nas cooperativas. Por esses argumentos, agravado com o fato de ser causa de desvio de produção, o processo de capitalização compulsória, na base do desconto sobre a produção recebida, não é recomendada como política administrativa a longo prazo.

\subsection{Formação de Capital Rotativo}

O Capital Rotativo, configurado em forma de fundo ou não, constitui-se instrumento moderno de capitalização de cooperativas, notadamente daquelas que se encontram em estado financeiro difícil. Os associados situam-se frente à esse processo de modo simpático, na medida em que há aporte de recursos em favor da cooperativa, mas esses valores voltam aos sócios, de forma gradual tal como as cooperativas americanas o caracterizam: 
«O plano é comparado a uma roda que puxa água, usada para gerar força, que faz funcionar a maquinaria da fábrica, fazendo retornar a água ao seu riacho.»

Esse modo de capitalização guarda, portanto, uma relação forte e direta entre quem fornece o capital e quem o recebe, de modo que o «patrocinador» é ao mesmo tempo o seu «beneficiário».

A devolução se dá no tempo e de forma escalonada, sem comprometer a estabilidade financeira que se visa alcançar pelo mesmo mecanismo de captação de recursos junto ao quadro social, tal qual uma represa, que quando enche, começa a devolver o excesso.

A legislação brasileira tratou da matéria, através da Resolução n. ${ }^{\circ}$ 10/74, de 22 de janeiro de 1974, do Conselho Nacional de Cooperativismo. O ordenamento jurídico enseja assim a criação do Capital Rotativo, nos termos abaixo sugeridos:

I. Os estatutos da cooperativa poderão admitir a criação do capital rotativo, fixando o modo de sua formação e as condições de sua retirada no prazo estabelecido ou nos casos de demissão, eliminação ou exclusão do associado.

II. A Assembléia Geral, desde que o assunto conste expressamente do edital de convocação, poderá criar o capital rotativo, observado o disposto no item anterior.

III. No que couber, aplicam-se ao capital rotativo as disposições legais referentes ao capital, notadamente as que se referem à manutenção do capital mínimo.

Os Estatutos Sociais poderão a partir desse regramento, adotar o seguinte cronograma de formação do CAPITAL ROTATIVO:

Art.-Fica instituído o capital rotativo, a ser formado pela integralização de capital no valor, de no mínimo, correspondente a: (definir volume produção, horas de trabalho, valor de operações), por associado, destinando-se ao saneamento financeiro da cooperativa.

Art.-Os associados poderão retirar seu capital rotativo no prazo de 3 (três) anos, em 3 (três) parcelas: de $30 \%$ (trinta por cento) no final do $1 .{ }^{\circ}$ exercício social; de $30 \%$ (trinta por cento) no final do $2 .^{\circ}$ exercício social e $40 \%$ (quarenta por cento) no final do $3 .^{\circ}$ exercício social.

$\S$ Único.-Mesmo em caso de demissão, eliminação ou exclusão de associados, as condições de retirada obedecerão os mesmos critérios deste artigo. 
Art.-Serão atribuídos juros de $12 \%$ (doze por cento) ao ano sobre o capital rotativo, cujo montante será pago nas condições do artigo anterior.

Art.-O capital rotativo deverá ser corrigido monetariamente no final de cada exercício, cujo valor resultante desta correção será incorporado às quotas-partes do capital social.

\subsection{Correção Monetária do Capital}

A Correção Monetária do balanço, instituída pelo Decreto-Lei n. ${ }^{\circ}$ 1.598/77 (E extinta pela Lei $n .^{\circ} 9.249$, de 26 de dezembro de 1995), previa a Correção Monetária das contas do Ativo Permanente e do Patrimônio Líquido, incluído neste último grupo, a conta «Capital Social Integralizado».

Através da Instrução Normativa n. ${ }^{\circ} 071$, de 29.12 .78 (D.O.U. 29.12.78) o Secretário da Receita Federal esclareceu no sub-item 18.1, que a conta "Capital Integralizado» não receberá em seu próprio saldo, o produto da Correção Monetária, devendo este ser creditado numa conta especial de «Reserva de Capital».

No caso específico das Sociedades Cooperativas, o tratamento a ser dado à Correção do Capital foi regulamentado através da Resolução do Conselho Nacional de Cooperativismo - CNC, n. ${ }^{\circ} 25 / 83$, posteriormente revogada e substituída pela Resolução CNC n. ${ }^{\circ} 27 / 84$ (D.O.U 24.09.84), conforme segue:

«b) contabilizar a correção monetária do capital na conta de "Reserva de Capital", que se transferirá para a conta de "Reserva de Equalização", salvo se a Assembléia Geral, se omissos os estatutos, determinar, por proposta do órgão de administração ou, através deste, por solicitação de associado, que seja incorporada, no todo ou em parte, à conta de capital dos associados»;

É possível o aumento do capital dentro da aplicação do instituto da Correção Monetária? A matéria demanda a explicação de fato hipotético da lei e do ajuste e atualidade entre a lei e o fato.

Do Fato: O capital de cooperativa X, em julho de 1985, representava apenas $12 \%$ do valor do saldo de sua própria correção monetária acumulada. Vê-se portanto que a cooperativa nunca incorporou a correção monetária ao capital e, com este procedimento, gerou reservas que podem se qualificar de indivisíveis ao quadro social. Esta práti- 
ca, embora a cooperativa não seja uma sociedade de capital, tem gerado frustrações ao quadro social, cujo capital não foi corrigido monetariamente, e assim não readquire seu valor "de poder aquisitivo». A inflação o corroeu e isto se constitui fator de desestímulo para novas capitalizações. Com o advento da estabilização financeira, a inflação estagnou e o capital readquiriu seu valor real. Porém, por vários anos, foi duramente penalizado, sem correção. Como corrigir esta anomalia?

Da Lei: Até 1977, as pessoas jurídicas corrigiam o grupo imobilizado com base no Decreto-Lei n. ${ }^{\circ}$ 1.302/73, mas a "Correção Monetária Especial» não beneficiava o capital das sociedades.

Com o Decreto-Lei n. ${ }^{\circ} 1.598 / 77$, foi possível corrigir a conta capital e o seu registro se dava em "conta de reserva de capital», mas passível de rateio.

Por muitos anos, as cooperativas brasileiras aguardaram, com ansiedade, a disciplina e a aplicação do Decreto-Lei n. ${ }^{\circ}$ 1.598/77 e, somente em 1983, através da Resolução n. ${ }^{\circ} 25$, do Conselho Nacional de Cooperativismo, ficou decidido que as sociedades cooperativas poderiam aumentar o capital com a reserva de correção monetária do capital. Esta decisão porém, tinha que aflorar de um consenso assemblear. Pela mesma resolução, a reserva de correção monetária especial foi qualificada de indivisível.

Em 1984, o C.N.C. novamente se manifestara sobre a matéria, baixando a Resolução n. ${ }^{\circ} 27$, mas sem alterar o conteúdo da Resolução . $^{\circ} 25$, neste particular.

Hoje face essas circunstâncias há que se questionar:

\section{1. ${ }^{\circ}$ Questionamento:}

Pode a cooperativa aumentar o seu capital com o saldo apresentado na conta «Reserva de correção monetária do capital»?

O aumento do capital, a partir da correção monetária do capital, foi possível nas sociedades cooperativas, a partir da Resolução n. ${ }^{\circ} 25$ do C.N.C., de 22 de novembro de 1983, e alterada, posteriormente, pela Resolução n. ${ }^{\circ}$ 27, de 22 de agosto de 1984.

Era legal aumentar o capital com o saldo apresentado na conta «Reserva de Correção Monetária do Capital», desde que o assunto seja suscitado em assembléia geral e tenha parecer favorável dos sócios. 
A partir de 31 de dezembro de 1995, por força do art. $4 .^{\circ}$, da Lei n. ${ }^{\circ}$ 9.249/95, não é mais possível aplicar a correção monetária.

\section{2. ${ }^{\circ}$ Questionamento:}

Já que o C.N.C somente se manifestou a respeito da indivisibilidade da correção monetária do capital em novembro de 1983, através da Resolução n. ${ }^{\circ}$ 25/83 e depois em agosto de 1984, através da ResoIução n. ${ }^{\circ} 27 / 84$, criando a "Reserva de Equalização», pode a cooperativa aumentar o seu capital com o saldo apresentado na conta «Reserva de Correção Monetária do Capital»»?

Analisou-se no item anterior a hipótese de aumento do capital com base na utilização do saldo apresentado na conta "Reserva de Correção Monetária do Capital» e com fundamento na interpretação analógica do art. 43, Lei n. ${ }^{\circ}$ 5.764/71, conclui-se que, se assim entender a maioria dos associados em assembléia geral, é legal a aplicação desta sistemática a partir da vigência da Resolução n. ${ }^{\circ} 25$, do C.N.C., até a data de 31 de dezembro de 1995.

\subsection{Taxação de contas-correntes dos associados}

Constitui-se uma forma indireta de capitalização a taxação das contas-correntes dos associados, cujos valores podem ser apropriados à conta capital.

Pergunta-se quanto à legalidade da cobrança dos débitos dos associados com a inclusão de taxas, inclusive a de juros.

Muitos associados se negam a pagar essas taxas e as discutem, inclusive, em juízo.

Há que se entender que a cobrança se fundamenta em vínculo obrigacional decorrente de ato cooperativo e não em contrato de natureza mercantil.

Atento para essa realidade, há Juizes de Direito que invocam as complexas relações cooperativas, não desconhecendo, assim, a natureza jurídica do ato cooperativo.

O cerne da questão da fixação das taxas sobre as contas-correntes dos associados devedores cinge-se na teoria do ato cooperativo, cujo termo jurídico tem, agora, proteção constitucional no: 
Art. 146:

«Cabe à lei complementar:

III. Estabelecer normas em matéria de legislação tributária, especialmente sobre:

c) adequado tratamento tributário ao ato cooperativo praticado pelas sociedades cooperativas». (C.F. 1988)

Foi a lei ordinária das sociedades cooperativas (Lei 5.764/71) quem deu consistência ao ato cooperativo, assim entendido:

Art. 79.-Denominam-se atos cooperativos os praticados entre as cooperativas e seus associados, entre estes e aquelas e pelas cooperativas entre si quando associadas, para a consecução dos objetivos sociais.

Parágrafo único. O ato cooperativo não implica operação de mercado, nem contrato de compra e venda de produto ou mercadoria.

Como regrou o parágrafo único, vê-se que o ato cooperativo não é de natureza mercantil, nem civil (contrato de compra e venda). Mas tem natureza jurídica cooperativa. É pacificada essa doutrina em dezenas de países que consagram a teoria do ato cooperativo.

Walmor Franke diria:

«O caráter orgânico da cooperativa, a sua natureza de "empreendimento-órgão" ou "empreendimento-membro", integrante das economias associadas, exprime-se, comumente, na afirmação de que a cooperativa é um "prolongamento" (prolongement), uma "extensão" (Dec. $n .{ }^{\circ}$ 60.597/67, art. 105), o "braço alongado" (verlaengerte Arm) das economias dos sócios. Daí também a lição da doutrina dominante no sentido de que os negócios internos entre cooperado e cooperativa (negócios-fim) não participam da natureza lucrativista das operações de mercado, já que são eles regidos pelo princípio de identidade ou da unidade do fim e porque não existe mercado entre a cooperativa e o associado no que respeita àqueles negócios. „ ${ }^{16}$

Denota-se que o associado é dono da cooperativa, não seu cliente, daí ser fácil entender que lhe cabe cobrir os custos operacionais na cooperativa. Os custos, via de regra são de recebimento de produtos e de fornecimento de bens e serviços.

$\mathrm{Na}$ hipótese dos associados não cobrirem esses custos no decorrer do exercício social, a cooperativa deverá rateá-los no final do exercício, o que também ficou determinado na regra legal cooperativa:

16 Franke, Walmor. Op. cit., p. 26. 
Art. 21.-O estatuto da cooperativa, além de atender ao disposto no art. 4. ${ }^{\circ}$, deverá indicar:

IV. a forma de devolução das sobras registradas aos associados, ou do rateio das perdas apuradas por insuficiência de contribuição para cobertura das despesas da sociedade; (Lei $n .^{\circ}$ 5.764/71)

Neste contexto, exceptuar algum sócio dessa obrigação do rateio, significa, na práxis, quebrar o princípio da igualdade de tratamento dos sócios, pois a sociedade teria que arcar com um ônus a mais, que determinado sócio se nega a suportar. Se todos os sócios negassem esse compromisso, isso significaria vontade em dissolver a cooperat.

A cooperativa, portanto, é "um braço alongado do associado», prestando-Ihe serviços, sem fins lucrativos.

O vínculo é de natureza associativa, de tal forma que: os sócios são a cooperativa e esta só tem razão de existência, se os sócios a querem manter. Mantê-la importa em suportar os seus custos operacionais, que lhes são repassados em função dos serviços prestados.

No caso da cooperativa cobrar antecipadamente uma taxa a maior, fica obrigada a devolver essa importância, na forma de sobras.

Resta esclarecer quanto à competência da fixação das taxas na cooperativa.

A competência, em regra, é da administração, pois esta cuida da gestão cooperativa. Os Estatutos Sociais preveem a matéria.

Convém, que se oriente, desde já, que as taxas de juros sobre as contas-correntes somente poderão ser, no máximo em $12 \%$ ao ano, como fixou a Constituição Federal no:

«Art. 192.-O sistema financeiro nacional, estruturado de forma a promover o desenvolvimento equilibrado do País e a servir aos interesses da coletividade, será regulado em lei complementar, que disporá, inclusive, sobre:

Parágrafo $3 .^{\circ}$. As taxas de juros reais, nelas incluídas comissões e quaisquer outras remunerações direta ou indiretamente referidas à concessão de crédito, não poderão ser superiores a doze por cento ao ano; a cobrança acima deste limite será conceituada como crime de usura, punido, em todas as suas modalidades, nos termos que a lei determinar». 
Assim, fica patente, que as cooperativas estão plenamente amparadas a cobrar de seus associados taxas, sejam administrativas, operacionais ou outras, com o fim de cobrir seus custos operacionais na prestação de serviços que realizam. Poderão fazê-lo de modo direto, apropriando o valor das taxas nas contas-correntes dos sócios ou de modo indireto, por ocasião do rateio dos prejuízos. Cobrados, poderão ser contabilizados na conta capital.

\section{Conclusão}

Vê-se, assim, que o Direito Cooperativo Brasileiro, quando trata do capital, filia-se à doutrina dos países mais avançados na proposta cooperativa e apresenta mecanismos legais para superação dos conflitos de interesse entre sócios e cooperativa. Esses conflitos refletem a complexidade do papel do capital, em ser ao mesmo tempo meio financeiro para a cooperativa crescer, sem, contudo, ter o poder de mando no processo decisório. 